\title{
Research on Biomedical Engineering
}

\author{
Alcimar B Soares, $\mathrm{PhD}$ \\ Editor-in-Chief
}

Dear readers

We are now coming to the end of another very exciting year for our Journal and for the Brazilian community of Biomedical Engineering.

Throughout the year we managed to implement a number of important steps towards our main goal of broadening the boundaries of the Journal. As we planned along the previous year, the first edition of RBEB has been issued with all the articles written in English, and it has been like that ever since. Submissions are now accepted only when written in English. Contrary to our initial concerns, it seems that our community managed to adapt to those changes with ease, since the number of papers submitted to the Journal did not decrease, when compared to last year's number.

Than came October, and we all met in the city of Uberlândia (MG-Brazil) for another Brazilian Congress on Biomedical Engineering. The CBEB 2014 set a new record for attendance, with more than 1300 people from all over the country and from abroad. But, above all, it gave us another opportunity to meet old friends, make new ones, exchange experiences and share knowledge.

Besides all that, a major change for our Journal has been set this year. After a very long discussion that involved the whole community, the General Assembly of the Brazilian Society of Biomedical Engineering (SBEB) decided that our journal should officially adopt the new title "Research on Biomedical Engineering - RBE", as of January 2015.

Therefore, this should be the last number using the title RBEB. However, our long history will not be lost. The first edition of RBE will be numbered 31(1), showing that this new title carries on the long tradition that started more than thirty years ago with the "Revista Brasileira de Engenharia - Caderno de Engenharia Biomédica".

RBE should arrive accompanied by a new website, more modern, interactive, dynamic and adapted to portable devices such as smartphones and tablets. And what's more, the electronic system for paper submission and review will be replaced by the ScholarOne Manuscripts - Thomson Reuters, a very powerful tool for manuscript submission, peer review and editorial management.

We sincerely hope that this latest step, along with all the actions taken over the past years by the Editorial board, will help to bring even more value to our Journal, take us to new grounds and contribute to a more thorough dissemination of the scientific achievements of our community.

Finally, I would like to thank each and everyone of you, readers and authors who have been contributing to the Journal since its foundation. A scientific journal strives for excellence always aiming at its public. Your continuous support shows that the Journal is on the right path. I must also thank the council and the board of directors of the Brazilian Society of Biomedical Engineering that have always been present and helping the editorial board whenever needed. My very special thank you to a huge group of people that dedicate part of their free time to help us achieving our end goal: the reviewers and the members of the editorial board. These people take the not so easy task of reading someone else's work and issuing an opinion on what has been achieved by the authors. That is the main pillar of a scientific journal. Hence, to all of you - hundreds, my warmest thanks and my sincere appreciation.

Happy holidays and a wonderful 2015 to us all. 